\title{
A Subgroup of First-Degree Relatives of Crohn's Disease Patients Shows a Profile of Inflammatory Markers in the Blood Which Is More Typical of Crohn's Disease Patients Than of Normal Individuals
}

\author{
Broide Efrat, ${ }^{1}$ Goren Iris, ${ }^{1}$ Hongbin Wang, ${ }^{2}$ Scapa Eitan, ${ }^{1}$ and Keisari Yona ${ }^{2}$ \\ ${ }^{1}$ Gastroenterology Institute, Assaf Harofeh Medical Center, Zerifin 70300, Israel \\ ${ }^{2}$ Department of Human Microbiology, Sackler Faculty of Medicine, Tel Aviv University, Ramat Aviv 69978, Israel
}

Received 5 October 2005; Accepted 19 December 2005

\begin{abstract}
Introduction. Family member with IBD is the greatest risk factor for developing the disease. The hematological profile of firstdegree relatives (FDRs) of Crohn's disease (CD) patients was studied in order to identify healthy FDRs at risk to develop disease. Materials and methods. Thirty CD patients, 90 FDRs, and 28 non-related individuals (controls) were enrolled. Hematological profile and C-reactive protein were determined. Results. All hematological parameters were significantly different in CD patients compared to controls, with significantly higher levels of CRP, WBC, PMN, MONO, and PLT and lower Hb and lymphocyte count. The hematological profile of FDRs showed values between the controls and CD patients with ten FDRs that their parameters matched those of CD patients and significantly different from other FDRs. This group was defined as high-risk relatives (HRRs). Conclusions. Analysis of the hematological profile and CRP level might be proven as a fast, reliable, and less money-consuming tool to identify FDRs with a probable increased risk to develop the disease.
\end{abstract}

Copyright (c) 2006 Broide Efrat et al. This is an open access article distributed under the Creative Commons Attribution License, which permits unrestricted use, distribution, and reproduction in any medium, provided the original work is properly cited.

\section{INTRODUCTION}

Familial aggregation of inflammatory bowel disease (IBD) was recognized almost four decades ago [1]. The prevalence of IBD in first-degree relatives is $13.4 \%-36 \%[2,3]$. There is a 10-13-fold increase in the familial risk of IBD in first-degree relatives of patients with ulcerative colitis (UC) or Crohn's disease (CD) [4]. The greatest risk factor for the development of IBD is having an affected family member with this disease. First-degree relatives, especially siblings, are at greatest risk, but the risk also extends to more distant relatives [5]. Quantification of this risk depends on a combination of ethnicity, the type of IBD-CD or ulcerative colitis, and the exact relationship between the person at risk and the proband [6]. In $\mathrm{CD}$ there is concordance for disease location as well as the type of disease among relatives [3, 7], and twin studies consider a strong evidence for genetic role in the etiology of $C D$ [8].

The age-adjusted relative risk in most studies is based on calculations using Stromgrën's methodology [9], a risk assessment, based on patients living to age 70 years. These studies give a lifetime risk of developing IBD for first-degree relatives of a CD proband of $4.8-5.2 \%$ for non-jews and $7.8 \%$ for jews $[6,7]$. Parents of children with IBD have been consistently found to be the first-degree relatives at lowest risk of developing IBD. The age-corrected risk for parents of a CD proband is $1.9-4.8 \%$ for non-jews and $2.2-3.8 \%$ for jews $[5,10]$.

Most studies on relatives of $\mathrm{CD}$ patients have analyzed intestinal permeability [10], luminal prostaglandins [11], hyaluronin release, or cytokine levels in the normal looking colonic mucosa compared to controls [12]. It was already published that the greatest risk factor for the development of IBD is having an affected family member [5]. Therefore, we aimed in our study to investigate the profile of hematological parameters, which indicate an immune and/or inflammatory active process of first-degree relatives (FDRs), of CD patients in order to identify healthy FDRs that might be at risk to develop $\mathrm{CD}$ in the future.

\section{MATERIALS AND METHODS}

\section{Participants}

Three groups of participants were included in the study. Group 1 consisted of thirty CD patients; group 2 of ninety 
TABLE 1: Demographic and clinical data of Crohn's disease, first-degree relatives, and control.

\begin{tabular}{|c|c|c|c|c|c|}
\hline & $\operatorname{Sex}(M / F)$ & $\begin{array}{c}\text { Mean age } \pm \text { SD } \\
\text { (years) }\end{array}$ & $\begin{array}{l}\text { Mean duration of } \\
\text { disease (months) }\end{array}$ & $\begin{array}{l}\text { Crohn's disease } \\
\text { activity index }\end{array}$ & Total number $(\mathrm{N})$ \\
\hline Crohn's disease & $21 / 9$ & $24.3 \pm 12.1$ & $58.3 \pm 86.7$ & $6.1 \pm 2.5$ & 30 \\
\hline First-degree relatives & $45 / 50$ & $31.9 \pm 16.5$ & & & 95 \\
\hline Control & $15 / 13$ & $36.8 \pm 12.6$ & & & 28 \\
\hline
\end{tabular}

healthy FDR of CD patients, and group 3 of twenty-eight normal controls. All CD patients were recruited from the Gastroenterology Outpatient Clinic in Assaf Harofeh medical Center in Israel. The inclusion criteria for group 1 were new onset CD or known patients who stopped the 5-aminosalycilic acid treatment one week prior to enrolment.

We excluded patients who were under immunosuppressive treatment or steroids. Activity index was assessed by using the Harvey-Bradshaw activity index [13].

We excluded FDRs with known chronic inflammation and those who were under anti-inflammatory or immunosuppressive treatment. Healthy controls were recruited from the other outpatient clinics in the same medical center. This study was approved by the ethics review committees of the hospital, and informed consent was obtained from all participants.

\section{Methods}

Ten $\mathrm{mL}$ of peripheral venous blood were drawn from all participants. Five $\mathrm{mL}$ in EDTA tubes were used for the complete blood count using SKS instrument, Coulter Company, and in the other $5 \mathrm{~mL}$ C-reactive protein (CRP) was determined by using Array Laser Nephelometer (Beckman Company). The hematological parameters examined were white blood count (WBC), hemoglobin (Hb), polymorphonuclear cells (PMN), lymphocytes (Ly), monocytes (MO), and platelets (PLT).

\section{Statistical analysis}

A two-tail unpaired Student $t$ test was used to compare between each of the parameters of the different groups. $P$ value $<.05$ was considered as statistically significant.

\section{RESULTS}

Demographic and clinical data are summarized in Table 1. CD patients were younger compared to FDRs and controls: mean ages of $24 \pm 12.1,31.9 \pm 16.5$, and $36.8 \pm 12.6$ years, respectively. Mean duration of disease was $58.3 \pm 86.2$ months with a mean activity index of $6.1 \pm 2.5$ (active disease is considered when score $>5$ ). All the seven examined inflammatory hematological parameters in the blood were found to be significantly different in group 1 (CD) population compared to group 3 (controls). In CD patients CRP, WBC, PMN, MO, and PLT levels were higher while $\mathrm{Hb}$ and Ly levels were found to be lower. A comparison between the same hematological parameters in groups 1 and 2 (CD versus FDRs), revealed similar significant differences, except for the WBC count. Yet, it is important to note that the parameters of the FDR group were between the control values and the $\mathrm{CD}$ patient values (Table 2).

We identified a group of ten FDRs with a mean age of $32.8 \pm 13.2$ years, who were classified as high-risk relatives (HRRs). In those relatives at least three parameters out of the seven were significantly different from the normal levels and similar to those in CD patients (Table 2). CRP and PLT counts were the leading parameters $(P<.001$ and .002$)$, respectively, followed by $\mathrm{Hb}(P<.03)$. However, all the other parameters behaved in the same manner showing a trend towards the CD patients values between the values of groups 1 and 3, despite not reaching a statistical significance (Table 2).

\section{DISCUSSION}

Despite the recent identification of Card 15 (NOD2) as a specific susceptibility gene $[10,14,15]$ for $C D$, the increased risk to relatives is difficult to quantify with precision [6]. We aimed in our study to investigate the profile of the routinely examined hematological parameters of FDRs of CD patients compared to CD patients and controls. An increase in these parameters might indicate an active inflammatory process, and therefore may be utilized as a simpler routine tool that will enable us to detect those FDRs who might have an increased risk to develop CD at the future. Our hypothesis is based on the established evidence that in CD patients there is an uncontrolled activation of the immune system, with a proinflammatory Th1 cytokines predominant expression $[16,17,31]$. We found seven parameters out of the nine examined (CRP, Hb, WBC, PMN, Ly, Mo, and PLT) that were significantly different between CD patients and controls, but not from FDRs. Based on these results, we identified ten FDRs who had at least three out of the seven hematological parameters which deviate from the normal controls by \pm 1 SD. We categorized them as HRR. The three parameters are of inflammatory type (higher CRP, PMN, and PLT). In HRRs all the seven examined parameters tended to be at the same trend as those of CD patients. There is a clear correlation between CD and an increased CRP level. CRP elevation in CD patients is associated with clinical disease activity, endoscopic inflammation, severely active histologic inflammation, and several other biomarkers of inflammation like Th1 cytokines: TNF- $\alpha$ and IL-1 $\beta$ [18-20]. Platelets are now recognized as cells deeply involved in inflammation. There is compelling evidence to support their role as an 
TABLE 2: Hematological parameters of CD, FDR, and control.

\begin{tabular}{|c|c|c|c|c|}
\hline \multirow{2}{*}{ Parameter } & \multirow{2}{*}{$\begin{array}{l}\text { Crohn's disease } \\
\text { patients (group 1) } 1,2\end{array}$} & \multicolumn{2}{|c|}{$\begin{array}{l}\text { First-degree relatives } \\
\text { (group 2) }\end{array}$} & \multirow{2}{*}{ Control (group 3$)^{5}$} \\
\hline & & Relatives $^{3}$ & $\begin{array}{l}\text { High-risk } \\
\text { relatives }\end{array}$ & \\
\hline CRP & $20.4 \pm 25.6$ & $3.5 \pm 8.3$ & $16.4 \pm 21.6$ & $1.9 \pm 1.6$ \\
\hline $\mathrm{Hb}$ & $12.2 \pm 1.5$ & $13.7 \pm 1.5$ & $13.0 \pm 1.5$ & $14.1 \pm 1.5$ \\
\hline $\mathrm{WBC}\left(\times 10^{3} / \mu \mathrm{L}\right)$ & $8.3 \pm 3.2$ & $7.4 \pm 3.2$ & $8.3 \pm 2.6$ & $7.0 \pm 1.5$ \\
\hline $\mathrm{PMN}\left(\times 10^{3} / \mu \mathrm{L}\right)$ & $5.5 \pm 2.6$ & $4.0 \pm 1.8$ & $5.3 \pm 1.8$ & $3.9 \pm 1.2$ \\
\hline $\operatorname{Ly}\left(\times 10^{3} / \mu \mathrm{L}\right)$ & $1.8 \pm 0.6$ & $2.3 \pm 0.6$ & $2.0 \pm 0.7$ & $2.2 \pm 0.6$ \\
\hline Mono $\left(\times 10^{3} / \mu \mathrm{L}\right)$ & $0.8 \pm 0.3$ & $0.6 \pm 0.3$ & $0.7 \pm 0.2$ & $0.6 \pm 0.1$ \\
\hline $\operatorname{PLT}\left(\times 10^{3} / \mu \mathrm{L}\right)$ & $315 \pm 92.1$ & $226.5 \pm 64.2$ & $310.1 \pm 111.3$ & $214.2 \pm 59.3$ \\
\hline Total number & 30 & 85 & 10 & 28 \\
\hline
\end{tabular}

${ }^{1}$ All parameters of this group except for WBC count were significantly different $(P<.05)$ from the group of all first-degree relatives.

${ }^{2}$ No differences were found between Crohn's disease patients and high-risk relatives.

${ }^{3}$ Statistically significant differences $(P<.05)$ were found between this group and high-risk relatives in the parameters of CRP, PMN, and PLT. ${ }^{4}$ Statistically significant differences $(P<.05)$ were found between this group and controls in the parameters of CRP, Hb, PMN, and PLT.

${ }^{5}$ All parameters of this group were significantly different $(P<.05)$ from the group of Crohn's disease patients.

active player in the mucosal tissue injury that occurs in CD $[21,22]$. Both CD and UC are associated with abnormalities of platelet number and function. In the peripheral circulation, the state of platelet activation is typically increased, and IBD-involved mucosa frequently contains platelet aggregates with mucosal microthrombi. The relevance of platelets dysfunction to IBD is still unclear, but there is solid evidence demonstrating that platelets, in addition to their traditional role in hemostasis, can also function as potent proinflammatory cells [23]. Upon activation, platelets secrete a large number of biologically active molecules able to induce or amplify an inflammatory process through many of the same cellular and molecular pathways conventionally utilized by immune cells mediating IBD [24].

Furthermore, the prevalence of anemia in patients with IBD ranges from $8.8 \%$ to $73.3 \%$ depending on the patient subpopulation [25]. Thirty years ago the Crohn's disease activity index was established by utilizing selected variables including the hemoglobin [26]. Since then, anemia is known to correlate with CD activity [27]. Another parameter which was increased in HRRs and was similar to the values of CD patients was the PMN count. Active CD causes an elevation of white blood count predominantly due to an increase in PMN leukocytes [27]. In the literature, it was allready published that increasd leukocyte addhesiveness/aggregation is a most useful indicator of disease activity in patients with IBD [28]. Phagocytosis and killing exerted by PMN were significantly reduced in CD patients [29]. In this regard, it should be mentioned that a decreased PMN phagocytic activity was found not only in CD patients but in their relatives compared to controls [30]. In addition to the above-mentioned inflammatory parameters, it was also found that in CD patients, there is an increased density and number of mononuclear cells in the intestinal lamina propria with an abnormal differentiation [16]. It is known that during exacerbation of $\mathrm{CD}$, the total number of the peripheral blood monocytes may be elevated in about $50 \%$ of the patients. Moreover, the total peripheral monocytes count of CD patients might be higher compared to healthy controls, as well as increased peripheral blood macrophage activation, with an increased phagocytosis and motility, spontaneous production of giant cells, superoxide anion, and lysosomal enzymes secretion $[17,31]$. We found as well that monocytes are increased in CD patients and in HRRs compared to the controls, but did not reach a significant difference. Similar results were reported in another study, where peripheral blood monocytes counts in patients with inflammatory bowel disease were raised compared with that of the control groups, but the difference did not reach statistical significance [32]. In addition to the conventional hematological parametrs, there is also evidence for elevated inflammatory cytokines in CD patients. Indaram et al measured the levels of cytokines in the colonic mucosa of asymptomatic first-degree relatives of CD patients. Increased levels of IL-2, IL-6, and IL-8 were found in the colonic mucosa. It is not clear if these increased levels are phenotyping markers for a genetic predisposition to developing CD later on, or whether they represent a preclinical damage that has to be further defined [33]. Our preliminary results show that the expression of TNF- $\alpha$ in peripheral mononuclear cells was higher in the group of 14 relatives as well as in CD patients. Unfortunately, we do not have enough data regarding TNF- $\alpha$ mRNA expression in HRRs due to the small population tested. Our findings in CD and HRRs concur with previous evidence that in CD patients there is an increase in hematological parameters that indicate an inflammatory process. Moreover, we are the first to show that a certain fraction of FDRs that we termed HRRs exhibits inflammatory characteristics similar to CD patients, despite being symptom-free. Thus we suggest a more simple as well as less money-consuming tool to select FDRs with a probable increased risk to develop the disease. We believe that further prospective studies will illuminate this important issue. 


\section{REFERENCES}

[1] Kirsner JB, Spencer JA. Family occurrences of ulcerative colitis, regional enteritis, and ileocolitis. Annals of Internal Medicine. 1963;59:133-144.

[2] Monsen U, Bernell O, Johansson C, Hellers G. Prevalence of inflammatory bowel disease among relatives of patients with Crohn's disease. Scandinavian Journal of Gastroenterology. 1991;26(3):302-306.

[3] Weterman IT, Pena AS. Familial incidence of Crohn's disease in The Netherlands and a review of the literature. Gastroenterology. 1984;86(3):449-452.

[4] Oostenbrug LE, van Dullemen HM, te Meerman GJ, Jansen PL. IBD and genetics: new developments. Scandinavian Journal of Gastroenterology. Supplement. 2003;(239):63-68.

[5] Bonen DK, Cho JH. The genetics of inflammatory bowel disease. Gastroenterology. 2003;124(2):521-536.

[6] Tysk C, Lindberg E, Jarnerot G, Floderus-Myrhed B. Ulcerative colitis and Crohn's disease in an unselected population of monozygotic and dizygotic twins. A study of heritability and the influence of smoking. Gut. 1988;29(7):990-996.

[7] Peeters M, Nevens H, Baert F, et al. Familial aggregation in Crohn's disease: increased age-adjusted risk and concordance in clinical characteristics. Gastroenterology. 1996;111(3): 597-603.

[8] Ahrenstedt O, Hallgren R, Knutson L. Jejunal release of prostaglandin E2 in Crohn's disease: relation to disease activity and first-degree relatives. Journal of Gastroenterology and Hepatology. 1994;9(6):539-543.

[9] Indaram AV, Nandi S, Weissman S, et al. Elevated basal intestinal mucosal cytokine levels in asymptomatic first-degree relatives of patients with Crohn's disease. World Journal of Gastroenterology. 2000;6(1):49-52.

[10] Hollander D. Crohn's disease-a permeability disorder of the tight junction? Gut. 1988;29(12):1621-1624.

[11] Russell RK, Satsangi J. IBD: a family affair. Best Practice \& Research Clinical Gastroenterology. 2004;18(3):525-539.

[12] Hugot JP, Chamaillard M, Zouali H, et al. Association of NOD2 leucine-rich repeat variants with susceptibility to Crohn's disease. Nature. 2001;411(6837):599-603.

[13] Harvey RF, Bradshaw JM. A simple index of Crohn's-disease activity. Lancet. 1980;1(8167):514-515.

[14] Tillil H, Kobberling J. Age-corrected empirical genetic risk estimates for first-degree relatives of IDDM patients. Diabetes. 1987;36(1):93-99.

[15] Ogura Y, Bonen DK, Inohara N, et al. A frameshift mutation in NOD2 associated with susceptibility to Crohn's disease. $\mathrm{Na}$ ture. 2001;411(6837):603-606.

[16] Braegger CP, MacDonald TT. Immune mechanisms in chronic inflammatory bowel disease. Annals of Allergy. 1994;72(2): 135-141.

[17] Mahida YR, Wu KC, Jewell DP. Respiratory burst activity of intestinal macrophages in normal and inflammatory bowel disease. Gut. 1989;30(10):1362-1370.

[18] Vermeire S, Van Assche G, Rutgeerts P. C-reactive protein as a marker for inflammatory bowel disease. Inflammatory Bowel Diseases. 2004;10(5):661-665.

[19] Solem CA, Loftus EV Jr, Tremaine WJ, Harmsen WS, Zinsmeister AR, Sandborn WJ. Correlation of C-reactive protein with clinical, endoscopic, histologic, and radiographic activity in inflammatory bowel disease. Inflammatory Bowel Diseases. 2005;11(8):707-712.

[20] Vatay Á, Bene L, Kovács Á, et al. Relationship between the tumor necrosis factor alpha polymorphism and the serum
C-reactive protein levels in inflammatory bowel disease. Immunogenetics. 2003;55(4):247-252.

[21] Danese S, Scaldaferri F, Papa A, et al. Platelets: new players in the mucosal scenario of inflammatory bowel disease. European Review for Medical and Pharmacological Sciences. 2004;8(5): 193-198.

[22] van Wersch JW, Houben P, Rijken J. Platelet count, platelet function, coagulation activity and fibrinolysis in the acute phase of inflammatory bowel disease. Journal of Clinical Chemistry and Clinical Biochemistry. 1990;28(8):513-517.

[23] Danese S, de la Motte C, Fiocchi C. Platelets in inflammatory bowel disease: clinical, pathogenic, and therapeutic implications. The American Journal of Gastroenterology. 2004;99(5): 938-945.

[24] Kapsoritakis AN, Potamianos SP, Sfiridaki AI, et al. Elevated thrombopoietin serum levels in patients with inflammatory bowel disease. The American Journal of Gastroenterology. 2000; 95(12):3478-3481.

[25] Wilson A, Reyes E, Ofman J. Prevalence and outcomes of anemia in inflammatory bowel disease: a systematic review of the literature. The American Journal of Medicine. 2004;116(suppl 7A):44S-49S.

[26] Best WR, Becktel JM, Singleton JW, Kern F Jr. Development of a Crohn's disease activity index. National Cooperative Crohn's Disease Study. Gastroenterology. 1976;70(3):439-444.

[27] Nielsen OH, Vainer B, Madsen SM, Seidelin JB, Heegaard NH. Established and emerging biological activity markers of inflammatory bowel disease. The American Journal of Gastroenterology. 2000;95(2):359-367.

[28] Arber N, Berliner S, Hallak A, et al. Increased leucocyte adhesiveness/aggregation is a most useful indicator of disease activity in patients with inflammatory bowel disease. Gut. 1995;37 (1):77-80

[29] Caradonna L, Amati L, Lella P, Jirillo E, Caccavo D. Phagocytosis, killing, lymphocyte-mediated antibacterial activity, serum autoantibodies, and plasma endotoxins in inflammatory bowel disease. The American Journal of Gastroenterology. 2000;95(6):1495-1502.

[30] Amati L, Caradonna L, Leandro G, et al. Immune abnormalities and endotoxemia in patients with ulcerative colitis and in their first degree relatives: attempts at neutralizing endotoxin-mediated effects. Current Pharmaceutical Design. 2003;9(24):1937-1945.

[31] Mazlam MZ, Hodgson HJ. Interrelations between IL-6, IL-1 $\beta$, plasma $\mathrm{C}$-reactive protein values, and in vitro $\mathrm{C}$-reactive protein generation in patients with inflammatory bowel disease. Gut. 1994;35(1):77-83.

[32] Mee AS, Berney J, Jewell DP. Monocytes in inflammatory bowel disease: absolute monocyte counts. Journal of Clinical Pathology. 1980;33(10):917-920.

[33] Indaram AV, Nandi S, Weissman S, et al. Elevated basal intestinal mucosal cytokine levels in asymptomatic first-degree relatives of patients with Crohn's disease. World Journal of Gastroenterology. 2000;6(1):49-52. 


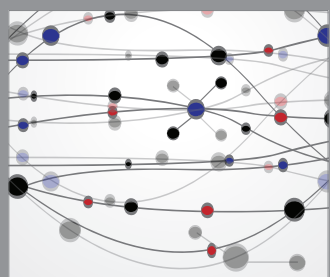

The Scientific World Journal
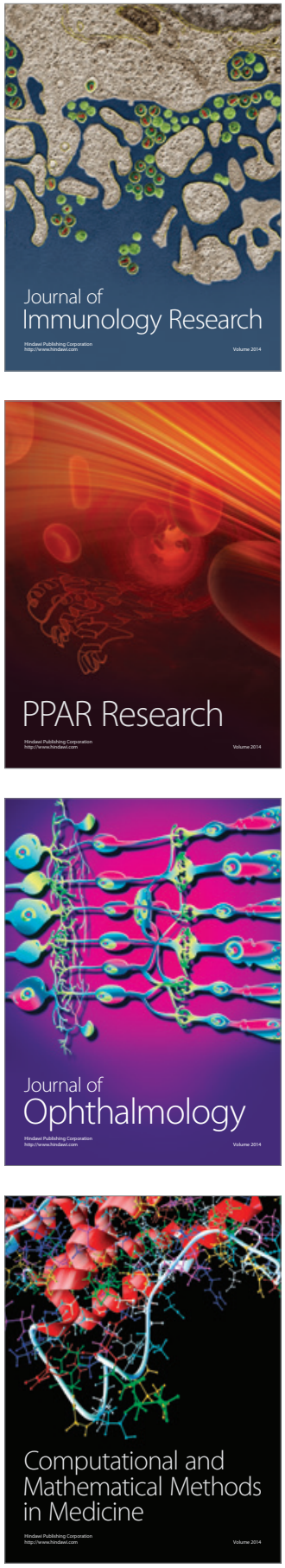

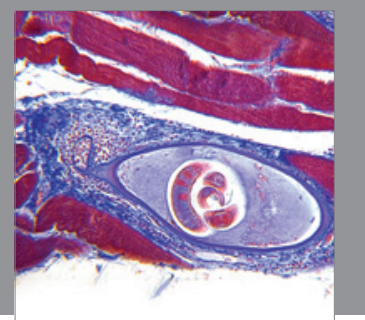

Gastroenterology

Research and Practice
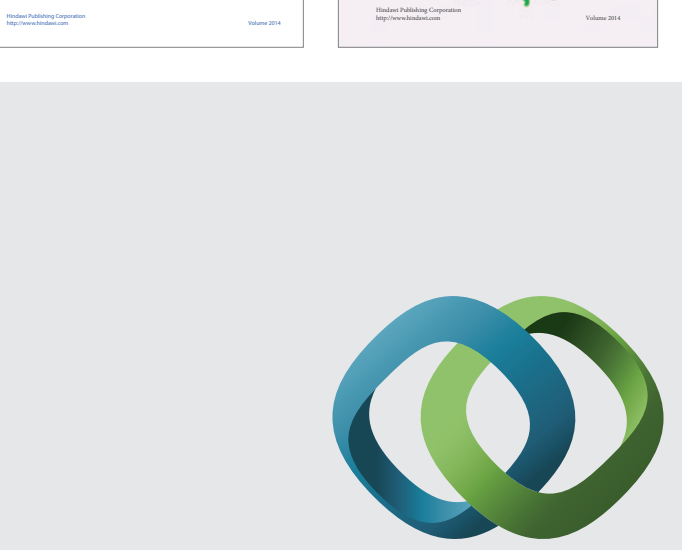

\section{Hindawi}

Submit your manuscripts at

http://www.hindawi.com
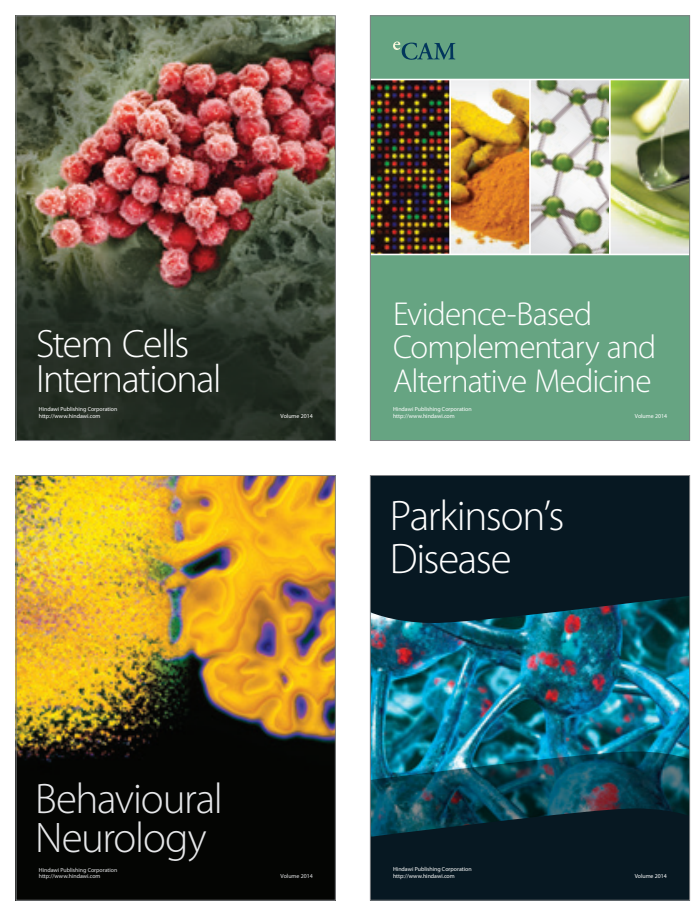

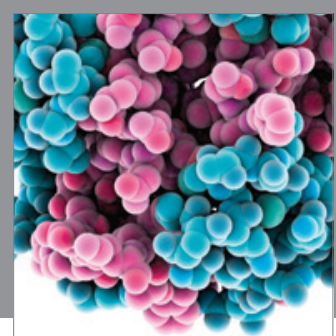

Journal of
Diabetes Research

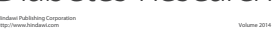

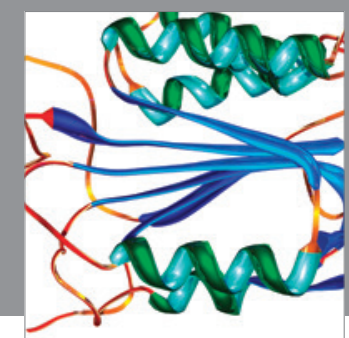

Disease Markers
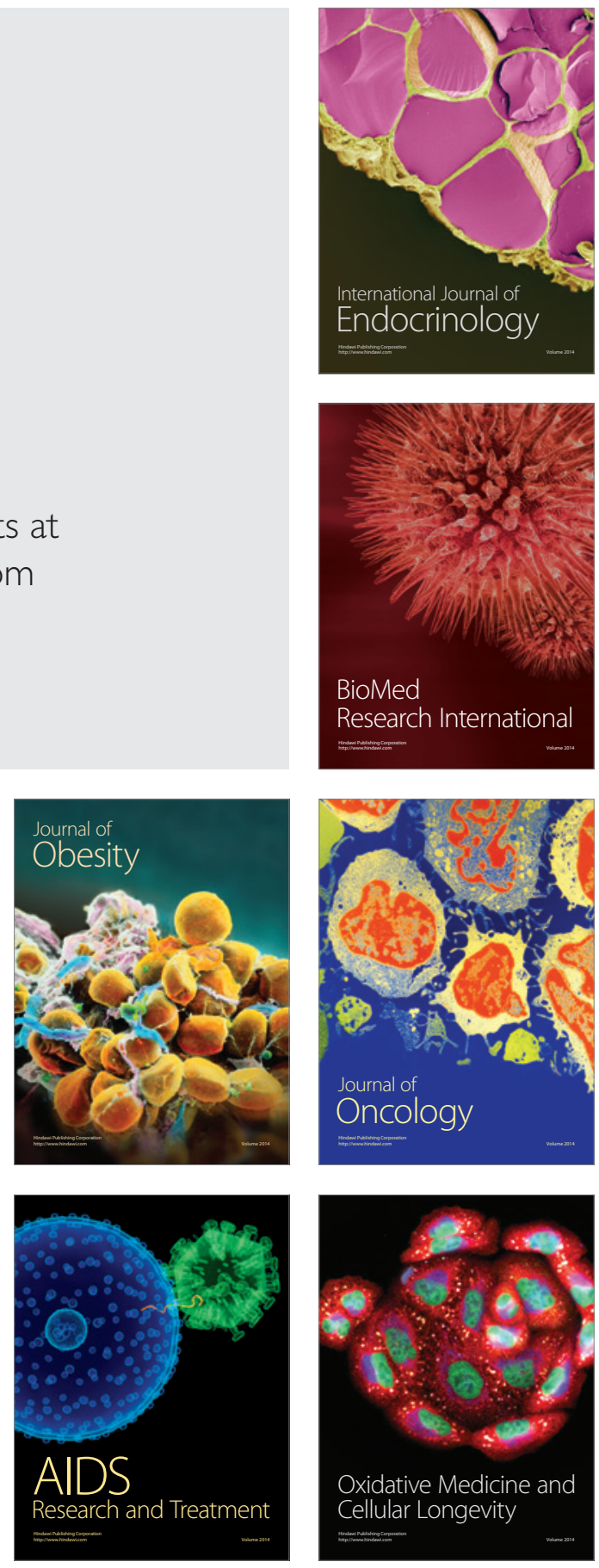